\title{
Can Infinitists Handle the Finite Mind Objection and the Distinction Objection?
}

\author{
Bin Zhao' ${ }^{1}$ \\ Received: 24 November 2020 / Revised: 30 December 2020 / Accepted: 28 January 2021 / \\ Published online: 9 February 2021 \\ (C) The Author(s) 2021
}

\begin{abstract}
This paper examines two objections to the infinitist theory of epistemic justification, namely "the finite mind objection" and "the distinction objection." It criticizes Peter Klein's response to the distinction objection and offers a more plausible response. It is then argued that this response is incompatible with Klein's response to the finite mind objection. Infinitists, it would seem, cannot handle both objections when taken together.
\end{abstract}

Keywords Epistemic justification - Epistemic regress · Infinitism · Justified beliefs · Second-order dispositional beliefs . The distinction objection $\cdot$ The finite mind objection $\cdot$ The sustaining relation

\section{Introduction}

Infinitism is a theory of epistemic justification. It claims that the structure of justificatory reasons is infinite and non-repeating. ${ }^{1}$ The theory contrasts sharply with other theories of epistemic justification such as foundationalism and coherentism. Foundationalists and coherentists both agree that the structure of justificatory reasons is

\footnotetext{
1 Strictly speaking, what I discuss in this paper is what Aikin (2008) terms "pure infinitism," according to which infinite and non-repeating chains of justificatory reasons are the only source of justification. But one could equally maintain that there are sources of justification other than infinite and non-repeating chains of justificatory reasons; this view is what he terms "impure infinitism." Impure infinitism can be combined with impure foundationalism or impure coherentism. Unlike pure infinitism, impure infinitism is not vulnerable to the dilemma I construct in Section 4. Because, as long as impure infinitists claim that there are sources of justification other than infinite and non-repeating chains of justificatory reasons, the distinction objection could be handled by appeal to the other sources of justification, e.g., basic beliefs or coherence, and this response is compatible with Klein's response to the finite mind objection. For more detailed discussions of impure infinitism, see Aikin (2008, 2010).
}

Bin Zhao

binz8@uci.edu

1 Department of Philosophy, University of California, Irvine, 85 Humanities Instructional Building, Irvine, CA 92697-4555, USA 
finite, though they disagree on whether the chain is repeating or not (Turri and Klein $2014 \mathrm{a}$, p. v). However, as is well known, both theories have their problems. Like these theories of epistemic justification, infinitism also has been met with a variety of objections. Among these are the finite mind objection and the distinction objection. Peter D. Klein, a key proponent of infinitism, has offered several responses to them.

In this paper, I argue that Klein's response to the finite mind objection is incompatible with the most plausible response to the distinction objection. The paper proceeds as follows: In section two, I sketch the infinitist theory of epistemic justification and its motivation. In section three, I explicate the finite mind objection and the distinction objection, and then Klein's responses to these two objections. In section four, I argue that his response to the distinction objection is problematic. I then offer a more plausible response on behalf of Klein, but I go on to show that this response is incompatible with his response to the finite mind objection. I conclude that infinitism, as least as it is defended by Klein, cannot find a safe path between the Scylla of the finite mind objection and the Charybdis of the distinction objection. Lastly, in section five, I consider a possible reply to my argument.

\section{Infinitism and Its Motivation}

We use reasons to justify our beliefs. These reasons, in turn, demand some further reasons to justify them. And these further reasons, in turn, demand yet other reasons to justify them, and so on. Through this process, our justificatory reasons form a chain. Concerning the structure of the chain, there are two main theories, i.e., foundationalism and coherentism. Roughly, the former claims that the chain ends with a basic reason which does not need another reason to justify it; the latter claims that the chain is repeating, and that reasons can re-occur at some later points on the chain. $^{2}$

As Klein points out, each of these two theories violates an intuitive principle. On the one hand, foundationalism violates the Principle of Avoiding Arbitrariness (PAA) which is intended to make explicit the intuition "that the chain of reasons cannot end with an arbitrary reason-one for which there is no further reason" (Klein 1999, p. 299). To put it formally,

"PAA: For all $x$, if a person, $S$, has a justification for $x$, then there is some reason, $r_{1}$, available to $S$ for $x$; and there is some reason, $r_{2}$, available to $S$ for $r_{1}$; etc." (Klein 1999, p. 299).

The notion of "availability" is made clear by the following passage:

"For a proposition to be available (Klein's emphasis) to $S$, it must either (i) be the propositional content of $S$ 's actual mental states, or (ii) be appropriately

\footnotetext{
${ }^{2}$ Strictly speaking, this is the claim of linear coherentism. The so-called "holistic coherentism" does not claim that.
} 
'hooked up' to $S$ 's actual mental states. For example, if $S$ believes that $p$, and $p$ (relevantly) entails $q$, then $q$ is available whether or not $S$ recognizes that consequence of her beliefs" (Klein 2008, p. 27).

On the other hand, coherentism violates the Principle of Avoiding Circularity (PAC) which "is intended merely to make explicit the intuition behind the prohibition of circular reasoning" (Klein 1999, p. 298). To put it formally,

"PAC: For all $x$, if a person, $S$, has a justification for $x$, then for all $y$, if $y$ is in the evidential ancestry of $x$ for $S$, then $x$ is not in the evidential ancestry of $y$ for $S^{\prime \prime}$ (Klein 1999, p. 298). ${ }^{3}$

By "evidential ancestry," Klein means "the links in the chains of reasons, sometimes branching, that support beliefs. For example, if $r$ is a reason for $p$, and $q$ is a reason for $r$, then $r$ is in the evidential ancestry of $p$ " (Klein 1999, p. 298).

Can an alternative theory satisfy both principles? Klein argues that infinitism can. Infinitism claims that the structure of justificatory reasons is infinite and non-repeating. Specifically speaking, infinitism claims that $S$ has a justification for a belief, $p$, only if there is an infinite and non-repeating chain of reasons available to $S$ such that beginning with $p$, each succeeding member is a reason for the immediately preceding one. He leaves it open what it takes for something to be a reason. Minimally, a reason is a belief that meets some normative or non-normative property while the nature of the relevant normative or non-normative property is unimportant for infinitism (Klein 1999, p. 298).

Unlike foundationalism, infinitism claims that the chain of reasons is infinitely long, which means reasons on the chain do not stop at some arbitrary point. Thus, it does not violate PAA. And unlike coherentism, infinitism claims that the chain of reasons is non-repeating, which means reasons on the chain do not occur at more than one point. Thus, it does not violate PAC. If we accept these two principles, then we can easily raise an argument by elimination for infinitism. ${ }^{4}$ Given this, it is no wonder that Klein says that "[i]t is the straight-forward intuitive appeal of these principles that is the best reason for thinking that if any beliefs are justified, the structure of reasons must be infinite and non-repeating (Klein's emphasis)" (Klein 1999, p. 299). ${ }^{5}$

\footnotetext{
3 This principle can only refute linear coherentism. It has nothing to do with holistic coherentism which claims that a belief is justified only if it is a member of a coherent set of beliefs. Nonetheless, Turri and Klein (2014b) agree with Sosa (1991) that holistic coherentism is, in fact, a disguised version of foundationalism, and so objections to foundationalism apply to holistic coherentism as well.

4 Recently, Engel (2014) develops another theory of epistemic justification which he calls "positism," according to which the chain of justificatory reasons can end with an unjustified reason. Strictly speaking, to raise an argument by elimination for infinitism, one must eliminate positism as well. While positism has not drawn enough attention from infinitists, what infinitists said about foundationalism also applies to positism, because positism, like foundationalism, violates the Principle of Avoiding Arbitrariness (PAA). Unlike basic beliefs in foundationalism, there is no defining feature of the unjustified reasons which, in turn, makes the problem for positism more trenchant.

5 For another crucial motivation for infinitism, i.e., the so-called "features argument," which argues that infinitism alone can explain that epistemic justification comes in degrees, and that it can be complete, see Fantl (2003) and Turri (2010).
} 


\section{Objections to Infinitism: The Finite Mind Objection and the Distinction Objection}

Like other theories of epistemic justification, infinitism has been met with a variety of objections. Some of these objections focus on its implausible requirements. For instance, the finite mind objection focuses on its requirement that there be an infinite number of reasons available to the human mind. Meanwhile, other objections focus on the corollaries of the theory. For instance, the distinction objection concerns whether infinitism can make a distinction between $S$ 's merely having available a justification for a belief and the belief's being justified for $\mathrm{S}$. In this section, I sketch these objections as well as Klein's responses to them.

\subsection{The Finite Mind Objection}

Since infinitism requires that there be an infinite number of reasons available to us if we have a justification for a belief, an obvious problem arises: how can there be an infinite number of reasons available to a finite mind? As mentioned before, though Klein does not specify what it takes for something to be a reason, he thinks that a reason is at least a belief available to the subject. Still, how can a finite mind have an infinite number of beliefs?

To examine this question, it is helpful to distinguish between different notions of belief. The narrowest notion of belief only admits occurrent beliefs: beliefs that are at the forefront of the conscious mind. For instance, the belief I have when I am considering that Paris is the capital of France. A slightly broader notion also admits first-order dispositional beliefs. A first-order dispositional belief is a belief that is held in the mind but not currently being considered. It could become an occurrent belief if it is retrieved from memory. Put in other words, it is a first-order disposition to think something occurrently under the appropriate circumstances. In this sense, I have a first-order dispositional belief that Paris is the capital of France because I have the disposition to think such a proposition occurrently if I can access it from my memory (Klein 1999, p. 308).

Most of us have the intuition that we cannot have an infinite number of occurrent beliefs or first-order dispositional beliefs in our finite lifetime. For instance, as Noah Lemos points out,

"it seems psychologically impossible for us to have an infinite number of beliefs. If it is psychologically impossible for us to have an infinite number of beliefs, then none of our beliefs can be supported by an infinite evidential chain" (Lemos 2007, p. 48). ${ }^{6}$

\footnotetext{
${ }^{6}$ This intuition is well-accepted among finitists. For another instance, see Huemer (2019). As he points out, the intuition does not rely on a method for counting beliefs. "The finite mind objection requires only that the answer to 'How many reasons do you have?' is definitely not 'infinity' [rather than some definite number]" (Huemer 2019, p. 185). However, Fumeton (2001) seems to be a significant dissenter as he claims that "we can and do have an infinite number of justified dispositional beliefs, enough and of the right sort to allow us to have justified beliefs even if all justification is inferential" (Fumeton 2001, p. 7).
} 
What's worse, if justification requires an infinite number of beliefs, then we have no justification for our beliefs since we do not have an infinite number of beliefs (BonJour 1976, p. 310). Infinitism thus seems too demanding as a theory of epistemic justification. This problem is known as the "finite mind objection."

Klein replies to this objection by advocating a very broad notion of belief, which allows for the possibility of our having an infinite number of beliefs thereby undermining the finite mind objection. According to Klein's notion, in addition to occurrent beliefs and first-order dispositional beliefs, second-order dispositional beliefs also count as beliefs. In contrast to occurrent beliefs and first-order dispositional beliefs, second-order dispositional beliefs are neither currently being considered nor in the mind though it is properly "hooked up with" our other occurrent and firstorder dispositional belief. It could become an occurrent belief or a first-order dispositional belief under the appropriate circumstances. For instance, though we have neither an occurrent belief nor a first-order dispositional belief that $366+71=437$, we have a second-order dispositional belief that $366+71=437$ because "[w]e are disposed to think (Klein's emphasis) that $366+71=437$ after a bit of adding given our belief that $6+1=7$, that $7+6=13$, etc." (Klein 1999, p. 308). ${ }^{7}$ In this sense, the proposition that $366+71=437$ is available to us because it is properly "hooked up with" our other beliefs and arithmetical skills.

To take another example, the proposition that Helena is the state capital of Montana is also available to us if we have the disposition to check the state capital listings in the World Almanac under the appropriate circumstances (Klein 2007a, p. 13), though we are not able to access the proposition from memory or infer it from occurrent beliefs. Put in other words, in virtue of the disposition to check the state capital listings in the World Almanac, we are able to think that Helena is the state capital of Montana occurrently. Thus, as Klein suggests, "[second-order] dispositions can be available to us, in the appropriate sense... All we need is the capacity to form new dispositions" (Klein 2000, p. 23). As a consequence, there are an infinite number of beliefs available to us in the sense that a second-order disposition to form the first-order disposition to think something also counts as a belief. Therefore, as Klein argues, the finite mind objection fails because it relies on a very narrow notion of belief. ${ }^{8}$

One may worry that the sense in which a second-order dispositional belief is available to us is not the epistemologically relevant sense that secures justification. To illustrate the point, consider the following case,

\footnotetext{
7 This distinction between first-order dispositional beliefs and second-order dispositional beliefs is more often framed as the distinction between dispositional beliefs and dispositions to believe. While the former are beliefs that are held in the mind but are not currently occurrent, the latter are dispositions to form a belief that is not already in the mind on conditions of prompting or attention. For the sake of consistency, I decided to use Klein's original terms in this paper. For a detailed discussion of the distinction, see Audi (1994).

${ }^{8}$ I shall not evaluate whether Klein's strategy is successful here as the paper aims to argue that infinitism fails even if Klein's response to the finite mind objection works. For related discussions, see Podlaskowski and Smith (2011, 2014), Smith and Podlaskowski (2013), and Turri (2013).
} 
"Suppose Sue believes that unicorns exist. She has no actual evidence for this in any ordinary sense... Unicorns, as chance would have it, actually exist, even though no one has ever had any evidence of this. Just now, bizarrely enough, there happens to be a baby unicorn hiding under Sue's bed. Suppose, further, that if someone were to ask Sue for justification for her belief in unicorns, she would start looking around for a unicorn. She would start by looking under the bed, whereupon she would see the baby unicorn, which she would happily cite as evidence that unicorns exist. But alas, no one ever asks Sue for justification, so she never looks for and never sees any unicorns" (Huemer 2019, p. 175).

It is argued that Sue's belief that unicorns exist is unjustified even though she has a second-order dispositional belief that there is a baby unicorn hiding under her bed. Therefore, the sense that a second-order dispositional belief is available to us is not the epistemologically relevant sense (Huemer 2019, p. 175).

Unfortunately, this worry mistakenly conflates $S$ 's merely having available a justification for a belief and the belief's being justified for $S$. I will say more about the distinction in the following section. Infinitists such as Klein are happy to acknowledge that Sue's belief that unicorns exist is unjustified. However, that is compatible with there being a justification for that belief. The case fails to show that the sense that a second-order dispositional belief is available to us is not the epistemologically relevant sense that secures justification.

\subsection{The Distinction Objection}

When it comes to justification and justified beliefs, it seems quite plausible to make a distinction between $S$ 's merely having available a justification for a belief and the belief's being justified for $S$. For instance, I have good reasons to believe that Novak Djokovic will win the Australian Open this year for a record of eight times because he had a perfect performance recently and the Australian Open suits his playing style. Nonetheless, I may believe that Novak Djokovic will be this year's winner by wishful thinking even though the above reasons are still available to me. In this case, I have available a justification for the belief that Novak Djokovic will win the Australian Open this year, although this belief is not justified for me. So $S$ 's merely having available a justification for a belief is different from the belief's being justified for $S$ (Fumerton 1995, pp. 91-92). As John Turri claims, "an adequate theory of justification must account for this distinction" (Turri 2009, p. 209). ${ }^{9}$

Since infinitism is mainly a theory of epistemic justification rather than justified beliefs, it is relatively unclear whether the theory leaves space for such a distinction. The worry here might be called "the distinction objection." ${ }^{10}$ Klein grants the

\footnotetext{
9 This distinction is more often framed as the distinction between propositional justification and doxastic justification which was first introduced by Firth (1978). For the sake of consistency, I decided to use Klein's original terms in this paper.

10 Another version of the distinction objection, according to which for any proposition we might believe, both it and its denial can be supported by infinite and non-repeating chains of reasons available to us, has been discussed by Aikin (2005, 2008), Cling (2004) and Post (1980, 1987).
} 
distinction but dismisses the worry. As he claims, though $S$ 's merely having available a justification for a belief and the belief's being justified for $S$ both require the necessary condition that there are infinitely many non-repeating reasons available to $S$, this does not mean that the distinction between them cannot be made in an infinitist theory (Klein 1999, pp. 324-325).

He then offers an account of the required distinction as follows:

$S$ has a justification for a belief, $p$, only if there is an infinite and non-repeating chain of reasons $\left(r_{1}, r_{2}, \ldots, r_{\mathrm{n}}, \ldots\right)$ available to $S$ such that beginning with $p$, each succeeding member is a reason for the immediately preceding one.

$S$ 's belief $p$ is justified, only if (1) there is an infinite and non-repeating chain of reasons $\left(r_{1}, r_{2}, \ldots, r_{\mathrm{n}}, \ldots\right)$ available to $S$ such that beginning with $p$, each succeeding member is a reason for the immediately preceding one, and (2) $S$ 's belief $r_{1}$ is playing the appropriate causal role in sustaining $S$ 's belief $p$, and $S$ 's belief $r_{2}$ is playing the appropriate causal role in sustaining $S$ 's belief $r_{1}, \ldots$ and $S$ 's belief $r_{\mathrm{n}}$ is playing the appropriate causal role in sustaining $S$ 's belief $r_{\mathrm{n}-1} \cdot{ }^{11}$ The length of the chain of sustaining satisfies the contextually determined requirements (Klein 1999, p. 315; 2007a, p.10; 2008, p. 29).

To clarify, the fact that $S$ 's belief $r_{1}$ is playing the appropriate causal role in sustaining $S$ 's belief $p$ does not mean that the belief $r_{1}$ is a sufficient cause of the belief $p$. It might be the case that the belief $r_{1}$ and other beliefs collectively cause the belief $p$. It also does not mean that the belief $r_{1}$ is a direct cause of the belief $p$. It might be the case that the belief $r_{1}$ causes another belief which in turn causes the belief $p$. In short, this claim is neutral on whether the sustaining belief is a contributing cause or a sufficient cause, as well as whether it is a direct cause or an indirect cause. In addition, as Klein (1999) claims, these conditions are individually necessary but not jointly sufficient because there are other necessary conditions for $S$ 's merely having available a justification for a belief and the belief's being justified for $S$. For instance, the condition that there must not be another reason, $r_{\mathrm{m}}$, available to $S$ that overrides $p$. Besides that, the reason why the length of the chain of sustaining is determined by the contextually determined requirements is that "which beliefs are being questioned or which can be taken as reasons is contextually determined" (Klein 2007a, p.10).

According to this account, the belief $p$ 's being justified for $S$ requires a stricter condition than $S$ 's merely having available a justification for the belief $p$. This account seems to handle the case of wishful thinking which is supposed to show that $S$ 's belief $p$ can be unjustified when $S$ has available a justification for the belief. If so, the distinction objection does not pose any substantial threat to infinitism when the theory is combined with the account given above. ${ }^{12}$

\footnotetext{
11 The so-called "sustaining" relation is more often called "the basing relation." Klein himself sometimes uses the latter term in some of his more recent papers such as Klein (2007b). For the sake of consistency, I decided to use "the sustaining relation" in this paper.

12 For related discussions of the distinction objection, see Bergmann (2007, 2014), Klein (2007a, 2007b, 2014b), Rosa (2016), Turri (2009, 2014).
} 


\section{Can Infinitists Handle the Finite Mind Objection and the Distinction Objection When Taken Together?}

In the above section, I sketched Klein's responses to the finite mind objection and the distinction objection. Two further questions remain. First, are these responses plausible? Second, are they compatible with each other? In this section, I argue that Klein's response to the distinction objection is problematic. I then offer a more plausible response on behalf of Klein. However, this response is incompatible with his response to the finite mind objection.

\subsection{Emergent Justification to the Rescue?}

Suppose that there is an infinite and non-repeating chain of reasons available to $S$ such that beginning with $p, r_{1}, r_{2}$, and $r_{3}$, each succeeding member is a reason for the immediately preceding one; and the contextually determined requirements require there be at least three reasons on the chain of sustaining to make his belief $p$ justified. Also, suppose that there are exactly three reasons $r_{1}, r_{2}$, and $r_{3}$ on the chain of sustaining.

According to Klein's account of a belief's being justified, $S$ 's belief $p$ is justified because it satisfies the contextually determined requirements. However, for any reason on the chain other than his belief $p$, the chain of sustaining contains fewer than three reasons. For instance, there are only two reasons on the chain of sustaining for the reason $r_{1}$, i.e., $r_{2}$, and $r_{3}$. As a result, $S$ 's belief $r_{1}, r_{2}$, and $r_{3}$ are not justified because they do not satisfy the contextually determined requirements. ${ }^{13}$ Then what makes $S$ 's belief $p$ justified if it is sustained by beliefs that are not justified? In a word, this account commits Klein to the implausible view that one's belief can be justified by beliefs that are not justified. ${ }^{14}$

Klein, of course, is fully aware of this charge. He goes on to argue that the charge is misguided as it is based on an incorrect view of justification, according to which "[i]nference cannot originate justification, it can only transfer (Ginet's emphasis) it from premises to conclusion" (Ginet 2005, p. 290). If this is the correct view of justification, then a belief cannot be justified unless all the beliefs in its evidential ancestry are justified. However, Klein rejects such a view and suggests that "[i]

\footnotetext{
13 One rebuttal is that the contextually determined requirements do not require a constant number of reasons on the chain of sustaining for any belief. This leaves open the possibility that $S$ 's belief $r_{1}, r_{2}$, and $r_{3}$ are also justified in this case. However, one can only make this rebuttal at the expense of committing oneself to the implausible view that some beliefs (e.g., $S$ 's belief $r_{3}$ ) can be justified without being sustained by another belief. If that is the case, then we are still not able to make a distinction between having available a justification for a belief and the belief's being justified for $S$ when it comes to these beliefs. That being said, the distinction objection comes back.

14 This is also a point pressed by Bergmann (2014) and Rosa (2016). It should be noted that I by no means regard this as a knock-down objection to Klein. One may try to avoid the implausible view by arguing that what determines the contextually determined requirements is not the number of beliefs on the chain of sustaining but whether there is some belief in a special propositional content on the chain of sustaining. Nonetheless, this response is still vulnerable to the objection raised in Section 4.2. For the sake of simplicity, I shall not delve into the response in more detail.
} 
nfinitism, like the plausible versions of coherentism, depicts justification as emerging when the set of propositions that are appropriately adduced as reasons expands" (Klein 2005b, p. 294).

According to such a view, we do not have to complete the chain of beliefs to justify something, since "[a]s the series [of beliefs] lengthens, warrant and credibility increase. Nothing prevents it increasing to the degree required for knowledge" (Klein 2005a, p. 281). A belief's being justified in this sense is what Klein calls "emergent justification." It is based on such a view that Klein claims that,

"[a] belief is... justified (at least to some degree) if we have located a good reason for holding it.... [E]ven if we have not yet located a good reason for holding the reason. But if we have a second reason for the first reason, the first reason is now (at least partially) doxastically justified and the doxastic justification of the original belief has further increased" (Klein 2007b, p. 28). ${ }^{15}$

He also makes an analogy to illuminate this view:

"It's like buying a car on payments. I am making progress in purchasing the car if I make a payment. I am making more progress if I make more payments. I had made that progress even if I run out of money and can't make the next payment" (Klein 2007b, p. 28).

Besides the analogy, one of the most potent arguments for the view of emergent justification in the literature is what John Turri terms "the argument from parity." Turri argues that finitists such as foundationalists commit themselves to the idea that a belief can be justified by being sustained by nondoxastic states such as experience. Furthermore, as he argues, the sustaining relation is the same no matter whether the belief is sustained by nondoxastic states or doxastic states. By parity of reasoning, a belief can be justified by being based on doxastic states such as beliefs. That is to say, epistemic justification emerges through inference. The argument can be summarized as follows:

1. If basing a belief on nondoxastic states creates justification, then basing a belief on doxastic states creates justification.

2. Basing a belief on nondoxastic states creates justification.

3. Basing a belief on doxastic states creates justification (Turri 2014).

I object to premise 2. I think it makes sense to claim that there are beliefs that are based on nondoxastic states and these very beliefs are justified. However, it is an open question whether these very beliefs are justified in virtue of their being based on nondoxastic states. To claim that a belief has these two features (i.e., being

\footnotetext{
15 Or put in other words, "the presuppositionally basic belief need not be reason-enhanced in order for it to reason-enhance the next proposition. The second proposition can rise to the level of Meno-knowledge" (Klein, 2014a, p. 111); "the reason, say $r$, for $x$ might not yet be doxastically inferentially justified. In such a case, if $r$ is deployed properly by $S$ for $p, p$ becomes reason-enhanced even though $r$ is not yet reason-enhanced" (Klein, 2014b, p. 115).
} 
justified and being based on nondoxastic states) is one thing; while to claim that one feature establishes another feature is another thing. What's worse, there are other ways to explain the justificatory status of the belief. For instance, the foundationalists can claim that the belief is justified by having a special propositional content. As long as different explanations are available to them, premise 2 cannot be taken for granted.

Klein's account of a belief's being justified presupposes the view of emergent justification. However, as has been shown in this section, this view is not well supported.

\subsection{An Account of a Belief's Being Justified?}

It has been argued that there are explanations other than emergent justification for the cases which infinitists use to show that justification is emergent. Klein may still argue that his view of emergent justification is superior to these explanations. However, there is another severe problem with his view which makes this strategy unsuccessful. To illustrate, let us reconsider the case in which there is an infinite and nonrepeating chain of reasons available to $S$ such that beginning with $p, r_{1}, r_{2}$, and $r_{3}$, each succeeding member is a reason for the immediately preceding one; and the contextually determined requirements require there be three reasons on the chain of sustaining to make his belief $p$ justified. Suppose that such a chain of reasons is available to $S$, and there are three reasons $r_{1}, r_{2}$, and $r_{3}$ on the chain of sustaining. According to the account, $S$ 's belief $p$ is justified.

The problem is that, though such a chain of reasons is available to $S$, there might be some other chains of reasons available to $S$ that also begin with $p, r_{1}, r_{2}$, and $r_{3}$. Among them, some chains are defective in the sense that some succeeding member on the chain is not a reason for the immediately preceding one. For instance, consider a chain of reasons on which what succeeds the reason that it is raining outside is the reason that the moon is made of cheese. The latter is not a reason for the former. If his belief that $r_{3}$ is sustained by a belief on the defective chain even though the right chain is also available to him, then it is unclear whether his belief $p$ is justified. $S$ also could succeed in providing $r_{1}, r_{2}$, and $r_{3}$ by a lucky guess even though the right chain is available to him. If that is the case, then it is also unclear whether his belief $p$ is justified (Turri 2009, pp. 210-212).

It is without a doubt that $S$ 's belief $p$ formed in these ways falls short of knowledge. The question is whether it is justified to the degree required for knowledge. Because the formation of the belief importantly depends on a defective reason or a lucky guess which can neither transfer nor generate justification, it is plausible to say that the belief is not justified, let alone justified to the degree required for knowledge.

Of course, it is always open to Klein to deny our intuition about justification and justified beliefs. As his account indicates, $S$ 's belief $p$ is justified to the degree required for knowledge. If so, we can further add that $S$ 's belief $p$ is true. As a result, we have a true belief justified to the degree required for knowledge which falls short of knowledge. It is of no surprise that a justified true belief is not an instance of 
knowledge. After all, it is argued that, no matter how strong a true belief is justified, as long as it is Gettiered in some way, it does not amount to knowledge (Zagzebski 1994). As long as Klein can argue that the reason why the belief falls short of knowledge is due to the belief's not satisfying the Gettier-proofing condition rather than the degree it is justified, ${ }^{16}$ he can maintain that $S$ 's belief $p$ is justified to the degree required for knowledge thus preserving his account of a belief's being justified.

Suppose that $S_{1}$ knows that $p$ while $S_{2}$ merely believes that $p$. The contextually determined requirements require there be three reasons on the chain of sustaining to make the belief $p$ justified. Suppose that such a chain of reasons is available to both $S_{1}$ and $S_{2}$ to the extent that there are three reasons $r_{1}, r_{2}$, and $r_{3}$ on the chain of sustaining. The difference between them is that $S_{1}$ 's belief $r_{3}$ is sustained by his reason $r_{4}$ while $S_{2}$ 's belief $r_{3}$ is based on his wishful thinking despite the reason $r_{4}$ 's being available to him.

According to Klein's account of a belief's being justified, $S_{2}$ 's belief $p$ is justified to the degree required for knowledge but does not satisfy the Gettier-proofing condition. If that is correct, then it should be the case that simply making it more justified does not turn it into an instance of knowledge because the reason why it falls short of knowledge has nothing to do with the degree it is justified. The simplest way to make it more justified, according to his account, is to provide an additional reason $r_{4}$ along the aforementioned infinite and non-repeating chain of reasons to sustain his belief that $r_{3}$ which in turn makes more justification emerge as the series of reasons lengthens. If so, then it is no longer possible for $S_{2}$ 's belief $p$ to be sustained by a belief on the defective chain or for $S$ to provide $r_{1}, r_{2}$, and $r_{3}$ by a lucky guess. There is no reason why $S_{2}$ 's belief $p$ formed in this way does not amount to knowledge as $S_{2}$ 's belief $p$ is now supported by reasons in the same way as $S_{1}$ 's belief $p$. Therefore, by making it more justified, $S_{2}$ 's belief $p$ can become an instance of knowledge. Therefore, contrary to our stipulation, $S_{2}$ 's belief $p$ is not justified to the degree required for knowledge even though it satisfies the requirement in the account.

Klein might respond that the reason why $S_{2}$ 's belief $p$ can become an instance of knowledge when the additional reason $r_{4}$ is provided is that it is no longer Gettiered. The worry is that, if providing the additional reason $r_{4}$ makes $S_{2}$ 's belief $p$ more justified as well as Gettier-proof, then it is unclear which feature turns the belief into an instance of knowledge. What's worse, the strict demarcation of justification and the Gettier-proofing condition presupposed in his response seems groundless if the belief's being more justified accompanies its being Gettier-proof. Klein might argue that it is a coincidence that these two features emerge together. However, if it is a coincidence, then it should be possible that the belief under discussion is rendered Gettier-proof without being more justified. However, the only way to render the belief (in the defective chain case or the lucky guess case) Gettier-proof is to provide the additional reason $r_{4}$ which necessarily makes the belief more justified according to his account. In a word, the strategy to explain the lack of knowledge in

\footnotetext{
16 There are many ways to cash out "the Gettier-proofing condition." It is beyond the purpose of this paper to explicate the condition. Klein himself is in favor of the defeasibility theory to account for the condition. See Klein (2017).
} 
this case in terms of the Gettier-proofing condition rather than the degree the belief is justified does not work.

The lesson learned is that simply providing contextually enough reasons which are not justified for one's belief along an infinite and non-repeating chain of reasons does not make the belief justified. In conclusion, Klein's account is too weak because an unjustified belief is deemed justified by it. It needs to be strengthened to account for a belief's being justified.

\subsection{A Dilemma for Infinitism}

As mentioned before, in Sections 4.1 and 4.2, by committing to the implausible view that one's belief can be justified by unjustified beliefs, Klein's account of a belief's being justified encounters some problems. These problems can be avoided if we can get rid of the implausible view. Thus, a more natural and plausible way to strengthen the account is to claim that only justified beliefs can justify other beliefs. That being said,

$S$ 's belief $p$ is justified only if (1) there is an infinite and non-repeating chain of reasons $\left(r_{1}, r_{2}, \ldots, r_{\mathrm{n}}, \ldots\right)$ available to $S$ such that beginning with $p$, each succeeding member is a reason for the immediately preceding one, and (2) $S$ 's belief $r_{1}$ is playing the appropriate causal role in sustaining $S$ 's belief $p$, and the belief $r_{1}$ is also justified. ${ }^{17}$

In the framework of infinitism, this amounts to suggesting that $S$ 's belief $p$ is justified, only if his belief $r_{1}$ is playing the appropriate causal role in sustaining his belief $p$, and his belief $r_{2}$ is playing the appropriate causal role in sustaining his belief $r_{1}, \ldots$ and his belief $r_{\mathrm{n}}$ is playing the appropriate causal role in sustaining his belief $r_{\mathrm{n}-1}, \ldots$ (this chain of beliefs is infinitely long). ${ }^{18}$ That is to say, $S$ 's belief $p$ is justified only if each succeeding belief on the infinite and non-repeating chain is playing the appropriate causal role in sustaining the immediately preceding belief. Though the strengthened account is significantly different from Klein's, it still marks the best attempt to account for a belief's being justified on the behalf of infinitists.

The good news is that infinitists are able to handle the distinction objection now; the bad news is that the solution is incompatible with Klein's response to the finite mind objection, according to which a second-order disposition to form the first-order disposition to think something occurrently under the appropriate circumstances (i.e., a second-order dispositional belief) also counts as a belief. The reason is as follows: it is dubious that a belief in this sense can play the appropriate causal role in sustaining another belief.

For instance, even if we grant that we have a second-order dispositional belief that $366+71=437$ in the sense that we are disposed to think that $366+71=437$

\footnotetext{
17 I will consider an alternative account of a belief's being justified which is less robust in Section 5.

18 If the chain of sustaining is finite, e.g., it requires that there be $\mathrm{n}$ reasons on the chain, then the problem of defective chain explicated in Section 4.2, i.e., what is playing the appropriate causal role in sustaining $r_{n}$ (e.g., it is raining outside) is a bad reason (e.g., the moon is made of cheese), would arise here.
} 
after a bit of adding given our belief that $6+1=7$, that $7+6=13$, etc., it is implausible that the belief that $366+71=437$ as a disposition to believe can play the appropriate causal role in sustaining our beliefs such as $366+71+3=440$. After all, the second-order dispositional belief that $366+71=437$ is not a belief held in the mind. In contrast, it is just a disposition to form an occurrent belief or a first-order dispositional belief that $366+71=437$ under the appropriate circumstances. One's occurrent belief that $366+71+3=437$ formed on a whim is not justified despite the existence of the second-order dispositional belief that $366+71=437$. That is because the second-order dispositional belief does not have the right causal efficacy. Once the disposition is manifested and an occurrent belief or a first-order dispositional belief that $366+71=437$ is formed, the newly formed belief can play the appropriate causal role in sustaining our beliefs such as $366+71+3=440$. Similarly, even if we grant that the proposition that Helena is the state capital of Montana is available to us if we were to check the state capital listings in the World Almanac under the appropriate circumstances, the second-order dispositional belief that Helena is the state capital of Montana cannot play the appropriate causal role in sustaining other beliefs such as Helena is the state capital of the fourth-biggest state. ${ }^{19}$

To conclude, Klein's response to the finite mind objection requires second-order dispositional beliefs, which are devoid of causal efficacy, to be counted as beliefs for the chain of reasons to be infinite; while the plausible account of a belief's being justified requires that each succeeding belief including second-order dispositional beliefs on the infinite and non-repeating chain is playing the appropriate causal role in sustaining the immediately preceding belief. Thus, the plausible account of the distinction between $S$ 's merely having available a justification for a belief and the belief's being justified for $S$ requires something which can never be satisfied by Klein's response to the finite mind objection. In short, there is an incompatibility between Klein's response to the finite mind objection and the plausible response to the distinction objection.

In conclusion, the finite mind objection and the distinction objection constitute a dilemma for infinitism. If Klein opts for his response to the finite mind objection, then infinitism becomes vulnerable to the distinction objection. If Klein opts for the plausible response to the distinction objection, then infinitism becomes vulnerable to the finite mind objection. Therefore, either the finite mind objection or the distinction objection obtains, and in both cases, infinitism is compromised.

\footnotetext{
19 An anonymous referee wonders if other beliefs such as the occurrent belief that $366+71+3=440$ counterfactually depend on the second-order beliefs such as $366+71=437$. It might be true that if the latter were not to obtain, then the former would not obtain. However, it is not true that if the latter were to obtain and the person was engaged in arithmetical reasoning, then the former would obtain. On the contrary, if the occurrent beliefs that $366+71=437$ (as well as $437+3=440$ ) were to obtain and the person was engaged in arithmetical reasoning, then the occurrent belief that $366+71+3=440$ would obtain. In that sense, other beliefs such as the occurrent belief that $366+71+3=440$ do not counterfactually depend on the second-order beliefs such as that $366+71=437$.
} 


\section{One Possible Reply}

I shall now briefly discuss one possible reply which is supposed to dissolve the incompatibility between Klein's response to the finite mind objection and the plausible response to the distinction objection.

This reply concerns the sustaining relation between beliefs. According to Klein's account of a belief's being justified for $S, S$ 's belief $p$ is justified, only if $S$ 's belief $r_{1}$ is playing the appropriate causal role in sustaining $S$ 's belief $p$ (Klein 1999, $\mathrm{p}$. 315 ; Klein 2008, p. 29). That is to say, there is a causal component in the sustaining relation between beliefs. ${ }^{20}$ This stance is plausible as most contemporary theories of the sustaining relation regard it as a causal relation; if the sustaining relation holds between belief $r_{1}$ and belief $p$, then there is a causal relation between them (Neta 2011, p. 111).

Contrary to Klein, some infinitists might maintain that there is not necessarily a causal component in the sustaining relation. If this reply is correct, then a secondorder dispositional belief could possibly sustain another belief without playing a causal role. If so, the aforementioned incompatibility is dissolved. An attractive way would be to replace the causal component in the sustaining relation with counterfactuals as follows:

$S$ 's belief $p$ is justified only if (1) there is an infinite and non-repeating chain of reasons $\left(r_{1}, r_{2}, \ldots, r_{\mathrm{n}}, \ldots\right)$ available to $S$ such that beginning with $p$, each succeeding member is a reason for the immediately preceding one, and (2) for any reason on the chain, if one were to reflect why he accepts it, then he would cite the succeeding reason on the chain.

This account of a belief's being justified does not commit us to the idea that each succeeding belief on the infinite and non-repeating chain is playing the appropriate causal role in sustaining the immediately preceding belief. This, in turn, makes it seem possible to handle both the finite mind objection and the distinction objection.

However, this account is also problematic. To illustrate, let us consider the case in which there is an infinite and non-repeating chain of reasons available to $S$ such that beginning with $p, r_{1}, r_{2}$, and $r_{3}$, each succeeding member is a reason for the immediately preceding one. Through wishful thinking, he forms the belief that $r_{2}$. By inference from that belief, he forms beliefs that $r_{1}$ and $p$ successively. After some time, he forgets that his belief that $r_{2}$ is obtained from wishful thinking. When asked why he accepts $r_{2}$, he thinks for a while and finally find that $r_{3}$ to be a reason for it. In addition, when asked why he accepts $r_{\mathrm{n}}(\mathrm{n} \geq 3)$ which is on the chain, he will cite $r_{\mathrm{n}+1}$ which is also on the chain to be a reason for it.

\footnotetext{
${ }^{20}$ Klein (2007b) claims that he is neutral on whether there is any causal component in the sustaining relation, and he thinks that "nothing significant depends upon remaining uncommitted about whether the beliefs with reasons as their propositional contents are causes of beliefs (Klein's emphasis)" (p. 26). However, as I have shown in Section 4, there is something significant that depends upon this point.
} 
It is clear that $S$ 's belief that $p$ is unjustified (at least before he finds that $r_{3}$ to be a reason for it) as it is inferred from a belief that is obtained from wishful thinking. However, according to the account under discussion, $S$ 's belief that $p$ satisfies the requirement for a belief's being justified. The account mistakenly conflates the state of a belief's being justified by a reason with the state of being able to provide a reason for the belief, but it is now widely accepted that one can be in one state without being in the other state. ${ }^{21}$ In conclusion, like Klein's account, this account is also too weak because an unjustified belief is deemed justified by it.

In sum, this reply is unable to dissolve the horns of the dilemma presented in the last section. While I grant that there may be other replies on behalf of infinitists I have not considered, but I doubt infinitists can find a safe path between the Scylla of the finite mind objection and the Charybdis of the distinction objection. Though infinitists have some seemingly plausible responses to these two objections respectively, they jointly constitute an insurmountable dilemma for infinitism.

\section{Conclusion}

The finite mind objection and the distinction objection are two objections to infinitism. As the main proponent of infinitism, Klein has offered responses to these two objections. Though his response to the distinction objection is problematic, there is another plausible response available to him. However, this response is incompatible with his response to the finite mind objection. Therefore, even if Klein can handle one objection, he leaves another objection untouched. As a result, there is no way he can overcome both objections. ${ }^{22}$

Open Access This article is licensed under a Creative Commons Attribution 4.0 International License, which permits use, sharing, adaptation, distribution and reproduction in any medium or format, as long as you give appropriate credit to the original author(s) and the source, provide a link to the Creative Commons licence, and indicate if changes were made. The images or other third party material in this article are included in the article's Creative Commons licence, unless indicated otherwise in a credit line to the material. If material is not included in the article's Creative Commons licence and your intended use is not permitted by statutory regulation or exceeds the permitted use, you will need to obtain permission directly from the copyright holder. To view a copy of this licence, visit http://creativecommons.org/licen ses/by/4.0/.

\footnotetext{
${ }^{21}$ For more detailed discussions of the distinction, see Alston (1985), Harman (1970), and Korcz (2000).

22 A much earlier version of this paper was presented at the Illinois Philosophical Association Conference in 2016. I am grateful to my commentator, Landon D. C. Elkind, and audiences on that occasion for many helpful comments and discussions. Thanks to Sven Bernecker, Mason Broxham, Dan Dake, Josh Dolin, James McGuire, Duncan Pritchard, Geoff Pynn, and an anonymous referee for Philosophia for helpful comments. I am particularly grateful to Mylan Engel Jr. and Michael Ramirez for numerous discussions on the issues of this paper.
} 


\section{References}

Aikin, S. F. (2005). Who is afraid of epistemology's regress problem. Philosophical Studies, 126, $191-217$.

Aikin, S. F. (2008). Meta-epistemology and the varieties of epistemic infinitism. Synthese, 163(2), $175-185$.

Aikin, S. F. (2010). Epistemology and the regress problem. New York: Routledge.

Alston, W. (1985). Concepts of epistemic justification. The Monist, 68(1), 57-89.

Audi, R. (1994). Dispositional beliefs and dispositions to believe. Nô̂s, 28(4), 419-434.

Bergmann, M. (2007). Is Klein an infinitist about doxastic justification? Philosophical Studies, 134(1), 19-24.

Bergmann, M. (2014). Klein and the Regress Argument. In J. Turri \& P. D. Klein (Eds.), Ad infinitum: New essays on epistemological infinitism (pp. 37-54). Oxford: Oxford University Press.

BonJour, L. (1976). The coherence theory of empirical knowledge. Philosophical Studies, 30, 281-312.

Cling, A. (2004). The trouble with infinitism. Synthese, 138, 101-123.

Engel, M. J. (2014). Positism: the unexplored solution to the epistemic regress problem. Metaphilosophy, 45(2), 146-160.

Fantl, J. (2003). Modest infinitism. Canadian Journal of Philosophy, 33, 537-562.

Firth, R. (1978). Are epistemic concepts reducible to ethical concepts? In A. Goldman \& J. Kim (Eds.), Values and morals (pp. 215-229). Dordrecht: D. Reidel.

Fumerton, R. A. (1995). Metaepistemology and skepticism. Lanham: Rowman \& Littlefield Publishers.

Fumerton, R. A. (2001). Classical Foundationalism. In Michael Raymond DePaul (ed.), Resurrecting Old-fashioned Foundationalism. Lanham: Rowman \& Littlefield Publishers, 1-20.

Harman, G. (1970). Knowledge, reasons, and causes. Journal of Philosophy, 67(21), 841-855.

Huemer, M. (2019). Finite minds. In B. Fitelson, R. Borges, \& C. Braden (Eds.), Themes from Klein: Knowledge, scepticism, and justification (pp. 171-187). Cham: Springer Nature Switzerland AG.

Ginet, C. (2005). Infinitism is not the solution to the regress problem. In M. Steup, J. Turri, \& E. Sosa (Eds.), Contemporary debates in epistemology (2nd ed., pp. 283-290). Malden: Wiley-Blackwell.

Klein, P. D. (1999). Human knowledge and the infinite regress of reasons. Philosophical Perspectives, 13, 297-325.

Klein, P. D. (2000). The failures of dogmatism and a new pyrrhonism. ActaAnalytica, 15(24), 7-24.

Klein, P. D. (2005a). Infinitism is the solution to the regress problem. In M. Steup, J. Turri, \& E. Sosa (Eds.), Contemporary debates in epistemology (2nd ed., pp. 274-282). Malden: Wiley-Blackwell.

Klein, P. D. (2005b). Reply to Ginet. In M. Steup, J. Turri, \& E. Sosa (Eds.), Contemporary debates in epistemology (2nd ed., pp. 291-294). Malden: Wiley-Blackwell.

Klein, P. D. (2007a). Human knowledge and the infinite progress of reasoning. Philosophical Studies, $134,1-17$.

Klein, P. D. (2007b). How to be an infinitist about doxastic justification. Philosophical Studies, 134, 25-29.

Klein, P. D. (2008). Useful false beliefs. In Q. Smith (Ed.), Epistemology: New essays (pp. 25-61). Oxford: Oxford University Press.

Klein, P. D. (2014a). No final end in sight. In R. Neta (Ed.), Current controversies in epistemology (pp. 95-115). New York: Routledge.

Klein, P. D. (2014b). Reasons, reasoning, and knowledge: a proposed rapprochement between infinitism and foundationalism. In J. Turri \& P. D. Klein (Eds.), Ad infinitum: New essays on epistemological infinitism (pp. 105-124). Oxford: Oxford University Press.

Klein, P. D. (2017). The nature of knowledge. In R. Borges, C. de Almeida, \& P. D. Klein (Eds.), Explaining knowledge: New essays on the Gettier problem (pp. 35-56). Oxford: Oxford University Press.

Korcz, K. A. (2000). The causal-doxastic theory of the basing relation. Canadian Journal of Philosophy, $30,525-550$.

Lemos, N. (2007). An Introduction to the theory of knowledge. Cambridge: Cambridge University Press.

Neta, R. (2011). The basing relation. In S. Bernecker \& D. Pritchard (Eds.), The Routledge companion to epistemology (pp. 109-118). New York: Routledge.

Podlaskowski, A. C., \& Smith, J. A. (2011). Infinitism and epistemic normativity. Synthese, 178, 515-527.

Podlaskowski, A. C., \& Smith, J. A. (2014). Probabilistic regresses and the availability problem for infinitism. Metaphilosophy, 45(2), 211-220. 
Post, J. F. (1980). Infinite regresses of justification and of explanation. Philosophical Studies, 38(1), $32-50$.

Post, J. F. (1987). The faces of existence: an essay in nonreductive metaphysics. Ithaca: Cornell University Press.

Rosa, L. (2016). Rational doxastic dispositions and the epistemic regress problem. Dialectica, 70(4), 589-607.

Smith, J. A., \& Podlaskowski, A. C. (2013). Infinitism and agents like us: Reply to Turri. Logos and Episteme, 4(1), 125-128.

Sosa, E. (1991). Knowledge in perspective. Cambridge: Cambridge University Press.

Turri, J. (2009). An infinitist account of doxastic justification. Dialectica, 63(2), 209-218.

Turri, J. (2010). Foundationalism for modest infinitists. Canadian Journal of Philosophy, 40(2), $275-283$.

Turri, J. (2013). Infinitism, finitude, and normativity. Philosophical Studies, 163(3), 791-795.

Turri, J. (2014). Creative reasoning. In J. Turri \& P. D. Klein (Eds.), Ad infinitum: New essays on epistemological infinitism (pp. 210-226). Oxford: Oxford University Press.

Turri, J., \& Klein, P. D. (2014a). Preface. In J. Turri \& P. D. Klein (Eds.), Ad infinitum: New essays on epistemological infinitism (pp. v-vi). Oxford: Oxford University Press.

Turri, J., \& Klein, P. D. (2014b). Introduction. In J. Turri \& P. D. Klein (Eds.), Ad infinitum: New essays on epistemological infinitism (pp. 1-18). Oxford: Oxford University Press.

Zagzebski, L. (1994). The inescapability of Gettier problems. Philosophical Quarterly, 44(174), 65-73.

Publisher's Note Springer Nature remains neutral with regard to jurisdictional claims in published maps and institutional affiliations. 